\title{
Ischemic proctitis 6 months after laparoscopic sigmoidectomy: a case report
}

\author{
Takuto Yoshida, Nobuki Ichikawa* (10, Shigenori Homma, Tadashi Yoshida, Shin Emoto, Yoichi Miyaoka, \\ Hiroki Matsui and Akinobu Taketomi
}

\begin{abstract}
Background: Ischemic colitis is a common disease; however, its pathophysiology remains unclear, especially in ischemic proctitis after sigmoidectomy. We present a rare case of ischemic proctitis 6 months after laparoscopic sigmoidectomy.
\end{abstract}

Case presentation: The patient was a 60-year-old man with hypertension, type 2 diabetes, and hyperlipidemia. He was a smoker. He underwent laparoscopic sigmoidectomy for pathological stage I sigmoid colon cancer and was followed up without any adjuvant therapy. Six months after his surgery, he complained of lower abdominal discomfort, bloody stools, and tenesmus. Colonoscopy showed extensive rectal ulcers between the anastomotic site and the anal canal, which was particularly severe on the anal side several centimeters beyond the anastomosis. We provided nonsurgical management, including hyperbaric oxygen therapy. The rectal ulcers had healed 48 days after the therapeutic intervention. He has not experienced any recurrence for 3.5 years.

Conclusions: While performing sigmoidectomy, it is important to consider the blood backflow from the anal side of the bowel carefully, especially for patients with risk factors of ischemic proctitis.

Keywords: Ischemic proctitis, Ischemic colitis, Sigmoid colon cancer, Bloody stool, Laparoscopic sigmoidectomy, Non-surgical management, Hyperbaric oxygen therapy

\section{Background}

Ischemic colitis is a common disease, and ischemic proctitis after sigmoidectomy is rare. The pathophysiology and definitive management remain unclear. We present a case of ischemic proctitis that occurred 6 months after laparoscopic sigmoidectomy and treated by non-surgical management.

\section{Case presentation}

A 60-year-old man underwent an occult bleeding test during his annual medical checkup, which showed positive results. Colonoscopy showed a type 1 tumor in the sigmoid colon (Fig. 1). The biopsy of the lesion showed

\footnotetext{
*Correspondence: n_ichi@d5.dion.ne.jp

Department of Gastroenterological Surgery I, Graduate School

of Medicine, Hokkaido University, W-7, Kita-ku, Sapporo N-15060-8638, Japan
}

well-differentiated adenocarcinoma. The patient had hypertension, type 2 diabetes, and hyperlipidemia. He had a history of smoking half a pack of cigarettes per day for 27 years, which he quit 15 years back. His family history was unremarkable. On physical examination, his abdomen was soft and non-distended. Laboratory data showed carcinoembryonic antigen (CEA) $6.1 \mathrm{ng} /$ $\mathrm{mL}$ and carbohydrate antigen (CA)19-9 $52 \mathrm{U} / \mathrm{mL}$. Radiographic contrast enema showed an approximately $3-\mathrm{cm}$ stricture in the sigmoid colon, and the apple core sign was positive. It was located between the upper part of the sigmoid colon and descending colon. The sigmoid colon was redundant (Fig. 2). Abdominal computed tomography $(\mathrm{CT})$ showed a contrast-enhanced lesion in the sigmoid colon without metastases (Fig. 3). He underwent laparoscopic sigmoidectomy with D3 lymph node dissection. The inferior mesenteric artery was ligated high. The sigmoid colon was resected at the level of the 


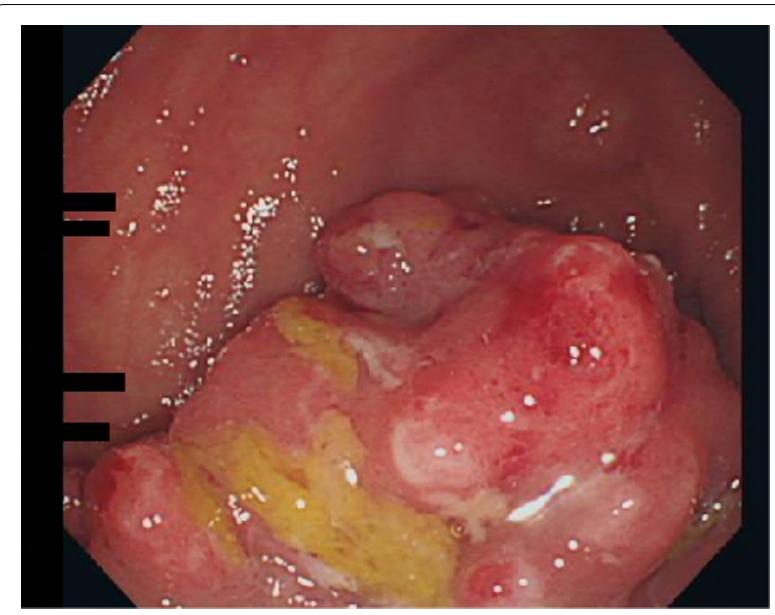

Fig. 1 Colonoscopy findings. Type 1 tumor in the sigmoid colon. A biopsy of the lesion reveals well-differentiated adenocarcinoma

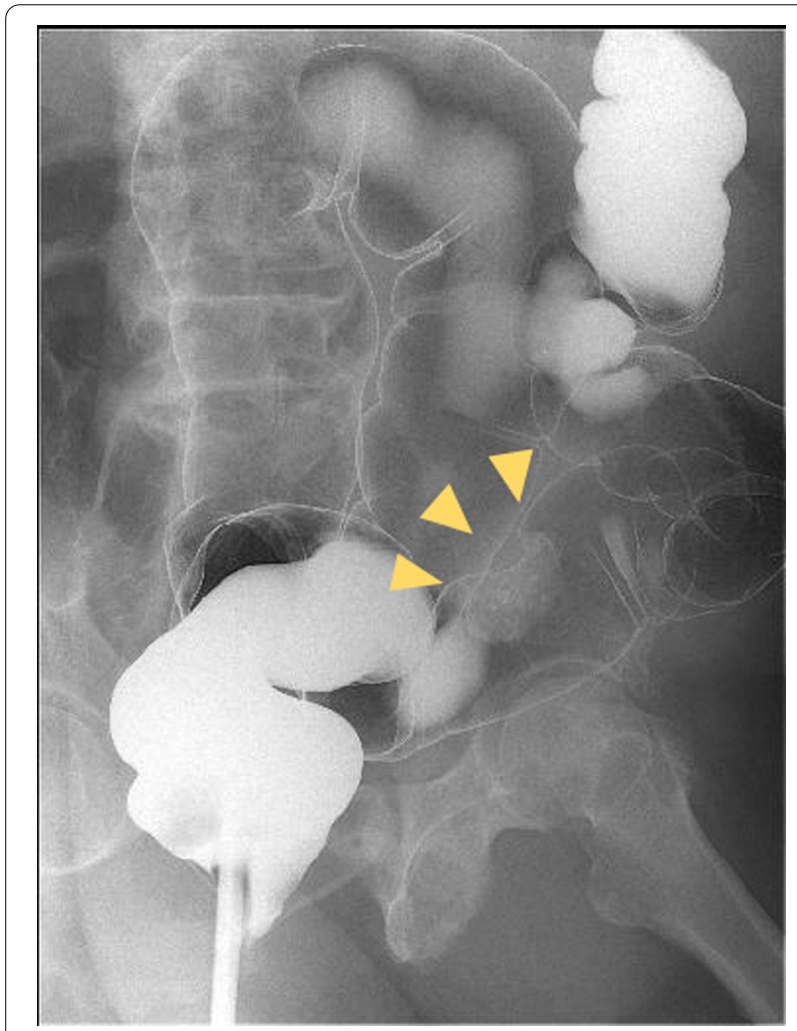

Fig. 2 Radiographic contrast enema findings. A 3-cm stricture can be seen in the sigmoid colon, and the apple core sign is positive (yellow arrow)

promontory, about $30 \mathrm{~cm}$ from the anal verge. We performed a double-stapling technique for the anastomosis. The length of resected specimen was $250 \mathrm{~mm}$, and the tumor was located $200 \mathrm{~mm}$ from the distal margin. The

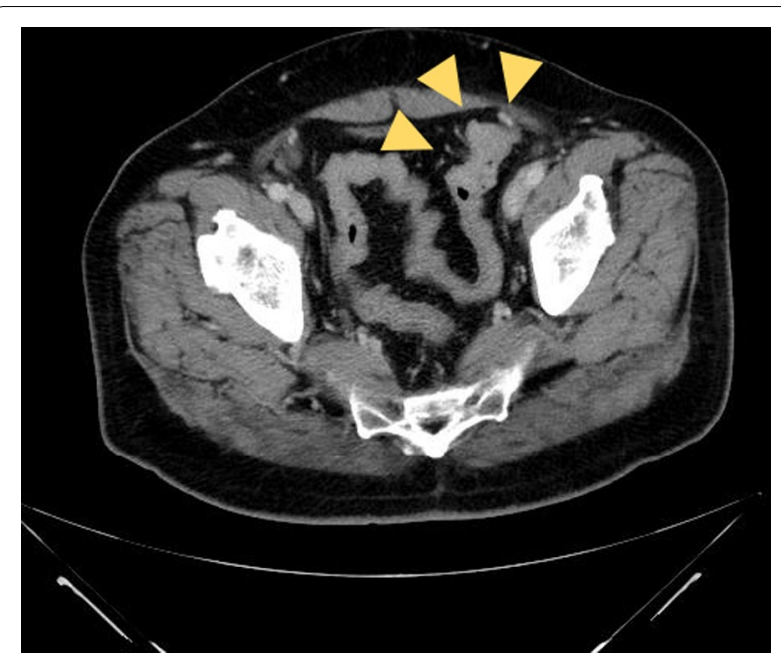

Fig. 3 Abdominal computed tomography findings. Abdominal computed tomography image shows a contrast-enhanced lesion in the sigmoid colon (yellow arrow). There are no metastases or ascites

surgical time was $135 \mathrm{~min}$, and blood loss was $10 \mathrm{~mL}$. His postoperative course was normal, and he was discharged on postoperative day 11 . The pathology was $\mathrm{S}$, type 2 , $35 \times 30 \mathrm{~mm}$, adenocarcinoma (tub2 > tub1), T2 (MP), N0, M0 pStage I. He was followed up without any adjuvant therapy. Six months after his surgery, he presented with mild lower abdominal discomfort, tenesmus, and bloody stools. Abdominal CT revealed extensive edematous changes in the rectum between the anastomotic site and the anal canal (Fig. 4). His symptoms had been deteriorating for 1 week with anal pain. Therefore, he was admitted to our department. His white blood cell count was $10,100 / \mu \mathrm{L}$, and C-reactive protein was $2.04 \mathrm{mg} / \mathrm{dL}$. Colonoscopy showed extensive circumferential rectal ulcers between the anastomotic site and the anal canal, which was especially severe and several centimeters beyond the anastomosis on the anal side. The mucosa around the anal canal was intact (Fig. 5). The stool culture was negative. The biopsy of the lesion showed erosive and regenerative colonic mucosa, and there was no malignancy or cytomegalovirus infection. He was diagnosed with ischemic proctitis and administered antibiotics. Since the patient did not have any peritoneal signs, we selected a nonsurgical treatment. Oral intake was stopped. We started with 10 sessions of hyperbaric oxygen therapy (HBO) for the patient on day 3 of admission. Prostaglandin E1 (PGE1) and Kampo medicines $\left({ }^{\circledR}\right.$ Saireito) were started on day 5 , and nitric oxide (NO) was started on day 12 . Oral intake was resumed on day 4. His rectal inflammation improved, and the last CT scan and colonoscopy showed normal findings 46 days after admission (Fig. 6). He was discharged on day 48. He continues to take PGE1 and has 

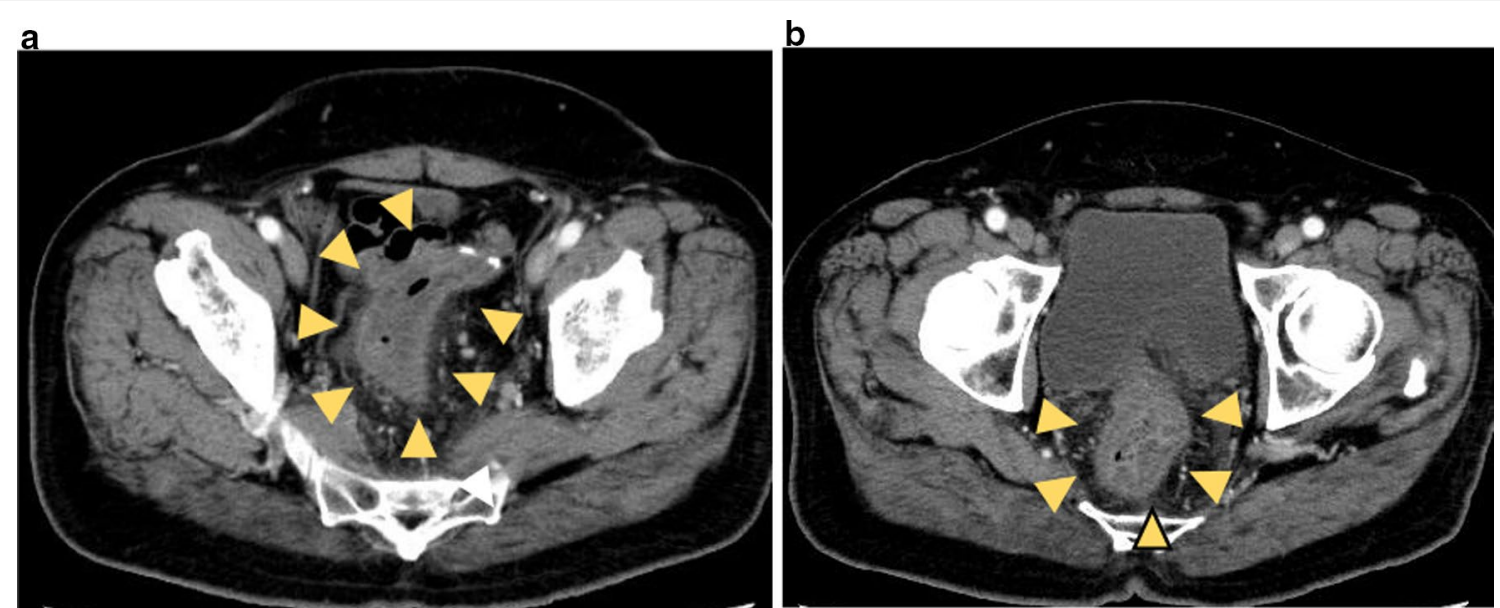

Fig. 4 Abdominal computed tomography findings. The images show edematous changes in the anal side of the anastomosis (yellow arrow). a The severest part of the ischemic lesion is not located adjacent to, but $\mathbf{b}$ is located at a short distance from the anastomosis towards the anal canal

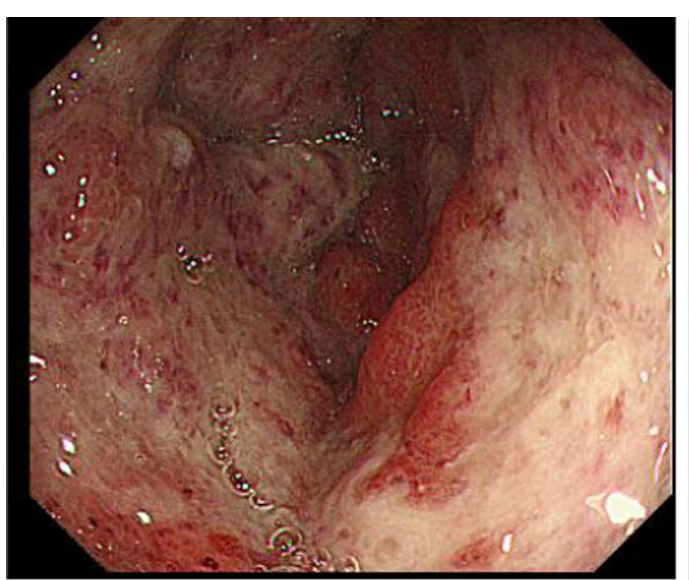

a

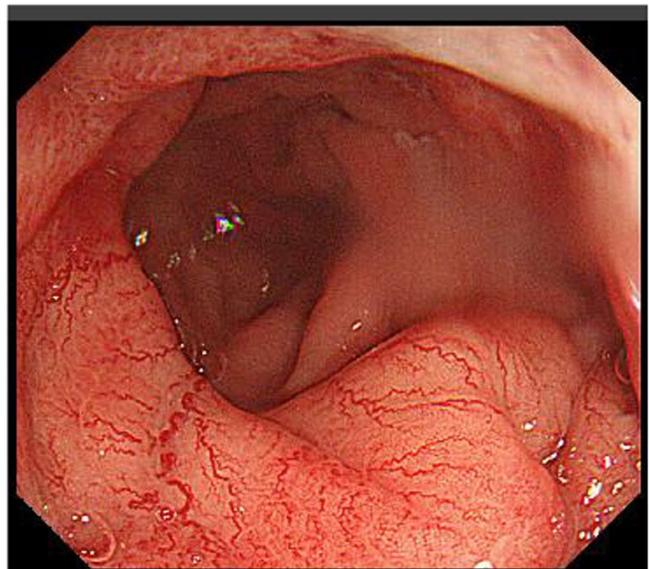

b

Fig. 5 Colonoscopy findings. a A circumferential ulcer is seen not adjacent to but near the anal side of the anastomosis. $\mathbf{b}$ The mucosa around the anal canal appears intact

used NO therapy for 1 year. He has remained symptomfree for 3.5 years.

\section{Discussion}

Ischemic colitis is defined as a localized and reversible ischemic colonic lesion $[1,2]$ that usually occurs at the ileocecal junction and around the Griffith's point and Sudeck's point [3]. Ischemic proctitis occurs in only $2-5 \%$ of cases of ischemic coloproctitis because of the abundant collateral blood supply of the rectum $[4,5]$. Moreover, ischemic proctitis after sigmoidectomy is rare [6]. There have been no reports on the prevalence of ischemic proctitis after sigmoidectomy. In general, the rectum is uncommonly affected by ischemia due to its relatively rich dual blood supply from both systemic and splanchnic circulation [7]. Bharucha et al. reported 328 ischemic colitis patients; of these, only 10 patients had isolated ischemic proctosigmoiditis [8]. In the present case, insufficient blood flow due to dissection of the inferior mesenteric artery may have contributed to the development of ischemic proctitis. Nelson et al. reported that an incidence of ischemic colitis after abdominal aortic surgery with inferior mesenteric artery resection is at least $0.5 \%$, suggesting that ischemic proctitis is very rare [9]. Here, we presented a rare case of ischemic proctitis that occurred 6 months after laparoscopic sigmoidectomy. The pathophysiology of ischemic proctitis after sigmoidectomy remains unclear. However, it was assumed to be related to several factors, including arteriosclerosis [9-12], venous congestion [13, 14], and anatomically 

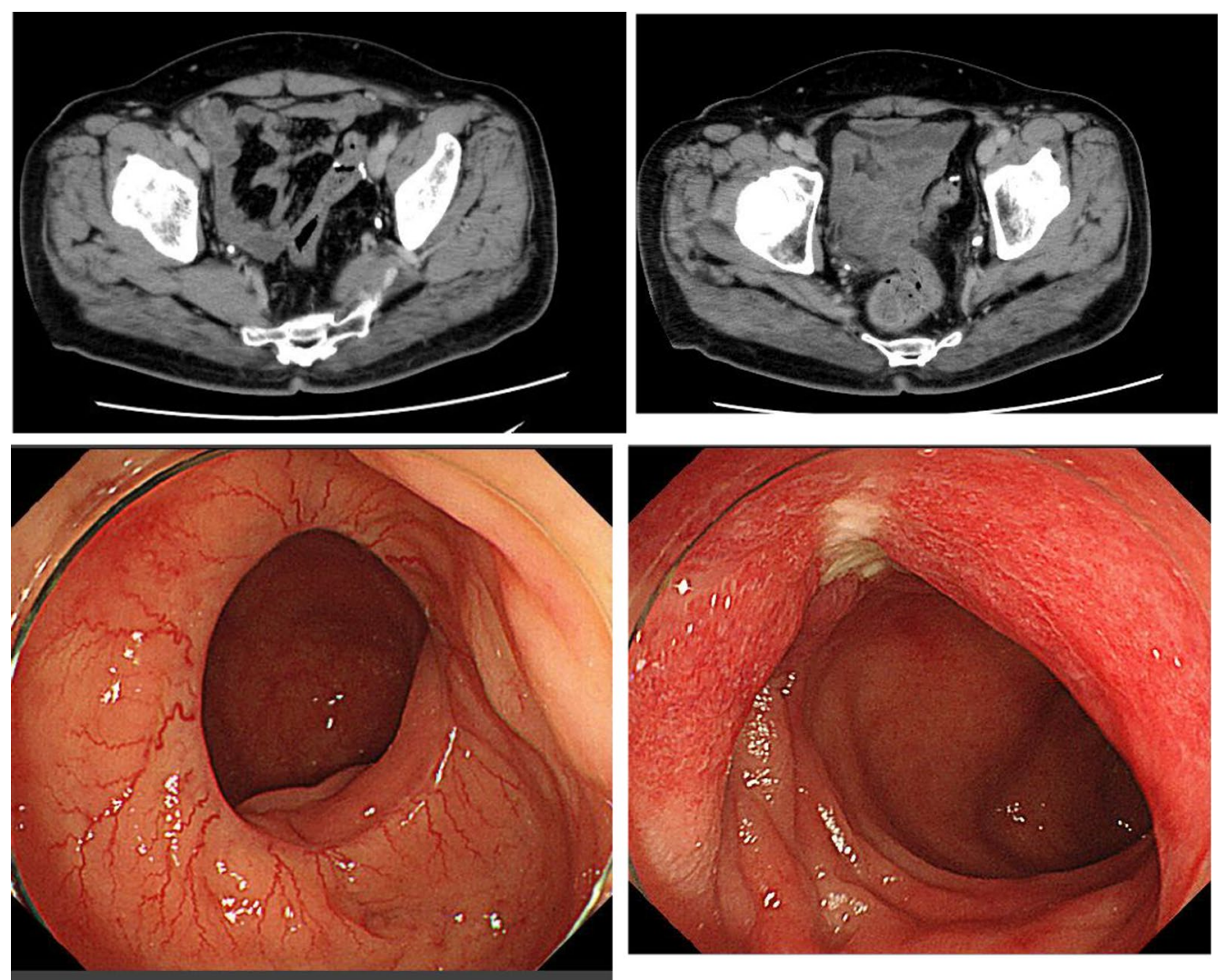

Fig. 6 Computed tomography and colonoscopy findings after non-operative management. Computed tomography was performed on the 46th day and colonoscopy on the 35th day. Edematous changes and circumferential ulcers show improvement

complicated areas such as the Sudeck's point [3, 15-18]. Sudeck's point is a watershed area and a weak blood supply point at the rectosigmoid junction $[15,17]$. An incomplete vascular anastomosis at the Sudeck's point would result in ischemic changes in the remaining rectosigmoid colon. This could cause anastomotic leakage after sigmoidectomy [18]. This patient's anastomotic site was at the sigmoid colon approximately $10 \mathrm{~cm}$ higher than the promontorium level with high ligation of the inferior mesenteric artery, which might be one of the causes of impaired vascular perfusion. However, the severest part of the ischemic lesion was not located at the anastomosis and the ulcers were spread extensively towards the anal canal. Additionally, the patient did not experience anastomotic leakage, which suggests that the Sudeck's point was not the sole cause of this patient's proctitis. We assume that the blood insufficiency was partial. Some inflammation in the underlying arteriosclerotic disease might have combined with the anatomical problem. Therefore, based on the present case, we believe that the blood backflow from the anal side should be considered more carefully, especially in patients with risk factors for ischemic proctitis such as arteriosclerotic disease. Evaluation of blood flow in the anastomotic bowel using indocyanine green is considered one of the methods for preventing bowel ischemia and anastomotic leakage [19]. Besides, since the ischemic proctitis occurred 6 months after sigmoidectomy in this case, intraoperative blood flow evaluation alone might not be sufficient as a preventive method. Considering the retrograde blood flow from the rectum, the most important thing is that the colon should not be resected distant from the anal verge in cases with redundant sigmoid colon.

The first-line treatment for ischemic colitis is nonsurgical management, including withholding oral intake and administration of antibiotics. In severe cases, surgery including colostomy or abdominoperineal resection is indicated [20]. In general, O'Neill et al. reported that aggravating risk factors of ischemic colitis include lack of rectal bleeding, peritonism, renal dysfunction, and rightsided ischemic colitis [21]. The patient did not have any peritoneal signs or aggravating risk factors. Furthermore, the patient's abdominal symptoms improved relatively fast with bowel rest, and surgical treatment was unnecessary. If the patient had abdominal discomfort with peritoneal signs or conservative treatment was unsuccessful, 
we would have performed the surgery. For non-surgical management, there have been reports of the use of HBO [22], vasodilators such as PGE1 [23], and NO [24]. The main aim of non-surgical management of ischemic proctitis is restoring tissue perfusion. Tissue perfusion is classified into three groups, namely, adequate perfusion, no perfusion, and marginal perfusion, called penumbra [25]. Ischemic-reperfusion injury induces leukocyte adherence to endothelial cells where they are activated. This activation results in the release of reactive oxygen species, which convert xanthine dehydrogenase into xanthine oxidase necessary for lipid peroxidation. This reaction induces tissue and organ injuries. In addition to tissue oxygenation and reducing edema via vasoconstriction [26], HBO inhibits $\beta 2$ integrin-mediated leukocyte adherence to endothelial cells in the animal model and decreases ischemic-reperfusion injury; thus, HBO exerts its greatest influence in the penumbra [27]. In the present case, there was no mechanical vessel obstruction, and the anastomotic site was also considered to be the penumbra; therefore, $\mathrm{HBO}$, which decreases the effect of ischemicreperfusion injury, was effective in this case. Patients without aggravating risk factors are good candidates for non-surgical management, including HBO.

\section{Conclusions}

Ischemic proctitis after sigmoidectomy might be related to underlying arteriosclerosis and anatomical blood flow insufficiency. It is important to carefully consider the blood backflow from the anal side, especially in patients with risk factors for ischemic proctitis.

\section{Abbreviations}

CA19-9: Carbohydrate antigen 19-9; CEA: Carcinoembryonic antigen; CT: Computed tomography; HBO: Hyperbaric oxygen therapy; NO: Nitric oxide; PGE1: Prostaglandin E1.

\section{Acknowledgements}

We would like to thank Elsevier Language Editing Services for English proofreading.

\section{Authors' contributions}

TY reported the case and wrote the manuscript. NI, HM, TY, SE YM, and HM were involved in treating the patient and helped draft the manuscript. NI, SH, and AT participated in critically revising the manuscript. All authors have read and approved the final manuscript.

\section{Funding}

No grant support or funding from public institutions or private enterprises was received for this case report.

\section{Availability of data and materials}

The dataset supporting the conclusions of this article is included in the article.

Ethics approval and consent to participate

Not applicable.

\section{Consent for publication}

Written informed consent was obtained from the patient for the publication of this case report and the accompanying images.

\section{Competing interests}

The authors declare that they have no competing interests.

Received: 24 December 2020 Accepted: 5 February 2021

Published online: 22 February 2021

\section{References}

1. Davis JE. Reversible vascular occlusion of the colon. Ann Surg. 1970:171:789-95

2. Marston A, Pheils MT, Thomas ML, Morson BC. Ischaemic colitis. Gut. 1966;7:1-15.

3. Yamazaki T, Shirai Y, Tada T, Sasaki M, Sakai Y, Hatakeyama K. Ischemic colitis arising in watershed areas of the colonic blood supply: a report of two cases. Surg Today. 1997;27:460-2.

4. Williams LF Jr, Wittenberg JA. Ischemic colitis: an useful clinical diagnosis, but is it ischemic? Ann Surg. 1975;182:439-48.

5. Maun D, Silverberg D, Steinhagen RM. Acute ischemic proctitis: report of four cases. Dis Colon Rectum. 2007:50:1082-6.

6. Matsuoka J, Taniai K, Kojima K, Kenmotsu M, Takai K, Okabe T, et al. A case rectal Dieulafoy's ulcer and successful endoscopic sclerotherapy. Acta Med Okayama. 2000;54:281-4.

7. Demetriou G, Nassar A, Subramonia S. The pathophysiology, presentation and management of ischaemic colitis: a systematic review. World I Surg. 2020;44:927-38.

8. Bharucha AK, Tremaine WJ, Johnson CD, Bads KP. Ischemic proctosigmoiditis. Am J Gastroenterol. 1996;91:2305-9.

9. Nelson RL, Briley S, Schuler JJ, Abcarian H. Acute ischemic proctitis. Dis Colon Rectum. 1992;35:375-80.

10. Brandt LJ, Feuerstadt P, Blaszka MC. Anatomic patterns, patient characteristics, and clinical outcomes in ischemic colitis: a study of 313 cases supported by histology. Am J Gastroenterol. 2010;105:2245-52.

11. Sharif S, Hyser M. Ischemic proctitis: case series and literature review. Am Surg. 2006;72:1241-7.

12. Ducarme $G$, Dochez V, Vallon $C$, Poirier $P$, Jean $M H$. Acute rectal ischemia following failed uterine artery embolization and emergency hysterectomy for postpartum hemorrhage. Int J Gynecol Obstet. 2015;129:81-2.

13. Chiang $\mathrm{CK}$, Lee $\mathrm{CL}$, Huang $\mathrm{CS}$, Huang $\mathrm{SH}, \mathrm{Wu} \mathrm{CH}$. A rare cause of ischemic proctosigmoiditis: idiopathic myointimal hyperplasia of mesenteric veins. Endoscopy. 2012:44:E54-5.

14. Sahara K, Yamada R, Fujiwara T, Koizumi K, Horiguchi SI, Hishima T, et al. Idiopathic myointimal hyperplasia of mesenteric veins: rare case of ischemic colitis mimicking inflammatory bowel disease. Dig Endosc. 2015;27:768-71.

15. Van Tonder JJ, Boon JM, Becker JHR, van Schoor AN. Anatomical considerations on Sudeck's critical point and its relevance to colorectal surgery. Clin Anat. 2007;20:424-7.

16. Boersema GSA, Wu Z, Kroese LF, Vennix S, Bastiaansen-Jenniskens YM, van Neck JW, et al. Hyperbaric oxygen therapy improves colorectal anastomotic healing. Int J Colorectal Dis. 2016;31:1031-8.

17. Greenberg MW. Blood supply of the rectosigmoid and rectum. Ann Surg. 1950;131:100-8.

18. Yamazaki T, Shirai Y, Sakai Y, Hatakeyama K. Ischemic stricture of the rectosigmoid colon caused by division of the superior rectal artery below Sudeck's point during sigmoidectomy: Report of a case. Surg Today. 1997:27:254-6.

19. Boni L, David G, Dionigi G, Rausei S, Cassinotti E, Fingerhut A. Indocyanine green-enhanced fluorescence to assess bowel perfusion during laparoscopic colorectal resection. Surg Endosc. 2016;30:2736-42.

20. Brandt LJ, Feuerstadt P, Longstreth GF, Boley SJ. ACG clinical guideline: epidemiology, risk factors, patterns of presentation, diagnosis, and management of colon ischemia (Cl). Am J Gastroenterol. 2015;1 10:18-44.

21. O'Neill S, Yalamarthi S. Systematic review of the management of ischaemic colitis. Color Dis. 2012;14:e751-63.

22. Nyabanga $\mathrm{CT}$, Kulkarni $\mathrm{G}$, Shen B. Hyperbaric oxygen therapy for chronic antibiotic-refractory ischemic pouchitis. Gastroenterol Rep. 2017;5:320-1. 
23. Ishihara Y, Seike M, Yokouchi I, Suda H, Ishitsuka S, Kakemura T, et al. Prostaglandin E1-effective, transient-type ischemic colitis developed after surgical resection of sigmoid colon cancer. A case report Dig Endosc. 2003;15:240-2.

24. Fotiadis C, Adamis S, Misiakos EP, Genetzakis M, Antonakis PT, Tsekouras DK. The prophylactic effect of L-arginine in acute ischaemic colitis in a rat model of ischaemia/reperfusion injury. Acta Chir Belg. 2007:107:192-200.

25. Harl MJ. Defining the Role of Hyperbaric Oxygen Therapy as an Adjunct to Reconstructive Surgery. Surg Clin North Am. 2020;100:777-85.

26. Nylander G, Lewis D, Nordstrom H, Larsson J. Reduction of postischemic edema with hyperbaric oxygen. Plast Reconstr Surg. 1985;76(4):596-601.
27. Thom SR. Functional inhibition of leukocyte B2 integrins by hyperbaric oxygen in carbon monoxide-mediated brain injury in rats. Toxicol Appl Pharmacol. 1993:123:248-56.

\section{Publisher's Note}

Springer Nature remains neutral with regard to jurisdictional claims in published maps and institutional affiliations.

\section{Submit your manuscript to a SpringerOpen ${ }^{\circ}$ journal and benefit from:}

- Convenient online submission

- Rigorous peer review

- Open access: articles freely available online

- High visibility within the field

- Retaining the copyright to your article

Submit your next manuscript at $\boldsymbol{\nabla}$ springeropen.com 